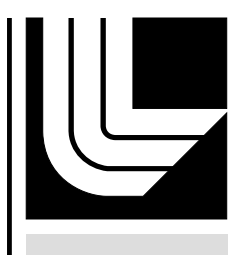

LAW RENCE LIVERMORE N A TION A L LABORATORY

\title{
UCRL-JRNL-204244
}

\section{Dosimetry of the 198Au Source used in Interstitial Brachytherapy}

L. Dauffy, L. Braby, B. Berner

May 19, 2004

Medical Physics 
This document was prepared as an account of work sponsored by an agency of the United States Government. Neither the United States Government nor the University of California nor any of their employees, makes any warranty, express or implied, or assumes any legal liability or responsibility for the accuracy, completeness, or usefulness of any information, apparatus, product, or process disclosed, or represents that its use would not infringe privately owned rights. Reference herein to any specific commercial product, process, or service by trade name, trademark, manufacturer, or otherwise, does not necessarily constitute or imply its endorsement, recommendation, or favoring by the United States Government or the University of California. The views and opinions of authors expressed herein do not necessarily state or reflect those of the United States Government or the University of California, and shall not be used for advertising or product endorsement purposes. 
Dosimetry of the ${ }^{198} \mathrm{Au}$ source used in interstitial brachytherapy

Lucile S. Dauffy,

Lawrence Livermore National Laboratory, 7000 East Ave., Livermore, California 94550

Leslie A. Braby

Nuclear Engineering Department, Texas A\&M University, College Station, Texas $77843-3133$

Barry M. Berner

Department of Radiology, Baylor College of Medicine, Houston, Texas 77030

(Received 


\section{ABSTRACT}

The American Association of Physicists in Medicine Task Group 43 report, AAPM TG-43, provides an analytical model and a dosimetry protocol for brachytherapy dose calculations, as well as documentation and results for some sealed sources. The radionuclide ${ }^{198} \mathrm{Au}\left(\mathrm{T}_{1 / 2}=2.70\right.$ days, $\left.\mathrm{E} \gamma=412 \mathrm{keV}\right)$ has been used in the form of seeds for brachytherapy treatments including brain, eye, and prostate tumors. However, the TG-43 report has no data for ${ }^{198} \mathrm{Au}$ seeds, and none have previously been obtained. For that reason, and because of the conversion of most treatment planning systems to TG-43 based methods, both Monte Carlo calculations (MCNP 4C) and thermoluminescent dosimeters (TLDs) are used in this work to determine these data. The geometric variation in dose is measured using an array of TLDs in a solid water phantom, and the seed activity is determined using both a well ion chamber and a High Purity Germanium detector (HPGe). The results for air kerma strength, $S_{k}$, per unit apparent activity, are 2.06 (MCNP) and 2.09 (measured) $\mathrm{U} \mathrm{mCi}^{-1}$. The former is identical to what was published in 1991 in the AAPM Task Group 32 report. The dose rate constant results, $\Lambda$, are 1.12 (MCNP) and 1.10 (measured), $\mathrm{cGy}^{-1} \mathrm{U}^{-1}$. The radial dose function, $\mathrm{g}(\mathrm{r})$, anisotropy function, $\mathrm{F}(\mathrm{r}, \theta)$, and anisotropy factor, $\phi_{\mathrm{an}}(\mathrm{r})$, are given. The anisotropy constant values are 0.973 (MCNP) and 0.994 (measured) and are consistent with both source geometry and the emitted photon energy. 


\section{INTRODUCTION}

Brachytherapy uses radioactive sources in various physical forms that are implanted either into or adjacent to malignant tissue. This technique has the advantage to maximize the tumor to normal tissue dose ratio by sparing the healthy cells surrounding the tumor. Advances in imaging technology and implant technique have led to the now common use of brachytherapy alone for the treatment of prostate cancer.

The two most commonly used radionuclides for the treatment of prostate cancer are ${ }^{125} \mathrm{I}$ and ${ }^{103} \mathrm{Pd}$. However, ${ }^{198} \mathrm{Au}$ remains an option for this type of cancer because of its dosimetric characteristics. Interstitial ${ }^{198} \mathrm{Au}$ implants for prostate cancer, introduced at Baylor College of Medicine in 1965, present several advantages. ${ }^{1}$ Firstly, the ${ }^{198} \mathrm{Au}$ average gamma ray energy is $412 \mathrm{keV}$, which provides both greater depth dose and less anisotropy in tissue compared to lower energy radionuclides. Secondly, ${ }^{198} \mathrm{Au}$ has a short half-life (2.70 days) that enables the delivery of the prescribed dose in a shorter time relative to radionuclides with a longer half-life. Long half-lives correspond to lower initial dose rates to the tumor, which can be ineffective in treating either fast-growing tumors or those with low $\alpha / \beta$ ratios. Finally, the solid form of the seed and its low production costs are also important benefits. R. G. Dale discussed the relative merits of ${ }^{198} \mathrm{Au}$ and ${ }^{125} \mathrm{I}$ and concluded at that time that there was little advantage in the more expensive ${ }^{125}$ I seeds $^{2}$.

The goal of this study is to determine the dosimetric characteristics of the ${ }^{198} \mathrm{Au}$ seed both experimentally and using a Monte Carlo code. The dosimetry follows that recommended by the American Association of Physicists in Medicine Task Group 43, AAMP TG-43. ${ }^{3}$ TG43 quantities are based on air kerma rates measured in air and dose rates measured in water. There has been extensive studies of the TG-43 dosimetry for ${ }^{192} \mathrm{Ir}^{4-13},{ }^{125} \mathrm{I}^{14-17}$, and ${ }^{103} \mathrm{Pd}$ 
seeds ${ }^{18-22}$, but not for ${ }^{198} \mathrm{Au}$ seeds. However, some data has been reported for ${ }^{198} \mathrm{Au}$ and will be useful for this work ${ }^{2,23-26}$.

Measurements of the dose to water were performed using $\mathrm{LiF}$ thermoluminescent dosimeters, TLDs, in a solid water phantom. Holes were drilled in the middle slab to accommodate the source and the TLDs. The entire phantom is a $30 \times 30 \times 30 \mathrm{~cm}^{3}$ cube. Monte Carlo simulations were performed using the Monte Carlo N-Particles code, MCNP 4C2 ${ }^{27}$. The source is placed in the middle of a simulated sphere of water or air, with the detectors placed around the source to simulate the experimental setup.

\section{METHODS}

\section{A. Source description}

The only design of interstitial gold seeds used in brachytherapy in the United States of America is manufactured by Engelhard Industries (700 Blair Road Carteret, NJ 07008) and distributed by Best Industries (model 81-02, 7643-B Fullerton Road, Springfield, VA 22153). This seed is shown in Fig. 1. The seed is a cylinder that is $2.5 \mathrm{~mm}$ in length and $0.8 \mathrm{~mm}$ in diameter. The core is made of gold ${ }^{197} \mathrm{Au}, 99.99 \%$ pure, which is $2.2 \mathrm{~mm}$ in length and 0.5 $\mathrm{mm}$ in diameter. It is encapsulated in a $0.15 \mathrm{~mm}$ shell of iridium-free platinum, which is 99.99 $\%$ pure.

Seed activation was done at the research reactor of Texas A\&M University. According to the LUND/LBNL nuclear data, ${ }^{198} \mathrm{Au}$ has a half-life of 2.6952 days, and beta decays to ${ }^{198} \mathrm{Hg}$, emitting gamma rays with an average energy of $412 \mathrm{keV}$, and X-rays with very low energies and yields. ${ }^{28}$ The finite dimensions of the source affects the dosimetry. For example, the source volume absorbs all beta rays emitted due to their short range (emitted beta rays 
have energies ranging from 285 to $1373 \mathrm{keV}$ ). Consequently no beta radiation contributes to

the dosimetry of ${ }^{198} \mathrm{Au}$ brachytherapy sources. The gamma spectrum is also modified by absorption and scattering of the gamma rays in the finite source volume.

\section{B. TG-43 quantities}

The improvement of TG-43, compared to the previous dose calculation methods, is that dose calculation formalism is based on measurable quantities: air kerma strength, $S_{k}$, dose rate constant, $\Lambda$, geometry factor, $\mathrm{G}(\mathrm{r}, \theta)$, radial dose function, $\mathrm{g}(\mathrm{r})$, and anisotropy function, $\mathrm{F}(\mathrm{r}, \theta)^{3,29,30}$. The polar coordinate system $(r, \theta)$ used in this dosimetric method is shown on Fig. 2, where the dose point is $\mathrm{P}(\mathrm{r}, \theta), \mathrm{r}$ is the distance from the dose point to the middle of the source of length $\mathrm{L}$, and $\theta$ is the angle between the longitudinal axis, $\mathrm{x}$, and $\mathrm{r}$. In this new formalism, the source strength is specified by $S_{k}$ instead of apparent activity. The tissue attenuation factor, $\mathrm{T}(\mathrm{r})$, used in traditional dose calculations is replaced by $\mathrm{g}(\mathrm{r})$, and the anisotropy of dose distribution is described by the anisotropy function, $F(r, \theta)$. Finally, the exposure rate constant, $\Gamma_{\delta}$, is replaced by the dose rate constant, $\Lambda$.

The dose rate at a point $\mathrm{P}(\mathrm{r}, \theta)$ near the source is then calculated using the following equation:

$$
\dot{\mathrm{D}}(\mathrm{r}, \theta)=\mathrm{S}_{\mathrm{k}} \Lambda \frac{\mathrm{G}(\mathrm{r}, \theta)}{\mathrm{G}\left(\mathrm{r}_{0}, \theta_{0}\right)} \mathrm{g}(\mathrm{r}) \mathrm{F}(\mathrm{r}, \theta)
$$

where the air kerma strength, $S_{k}$, is in $\left[\mu G y \mathrm{~m}^{2} \mathrm{~h}^{-1}\right]$ or in $\left[\mathrm{cGy} \mathrm{cm}^{2} \mathrm{~h}^{-1}\right]$, which is given the special unit $[\mathrm{U}]$, the dose rate constant, $\Lambda$, is in $\left[\mathrm{cGy} \mathrm{h}^{-1} \mathrm{U}^{-1}\right]$, and the geometry factor, $\mathrm{G}(\mathrm{r}, \theta)$, is in $\left[\mathrm{cm}^{-2}\right]$. Both the radial dose function, $\mathrm{g}(\mathrm{r})$, and the anisotropy function, $\mathrm{F}(\mathrm{r}, \theta)$, are unitless. 
These AAPM TG-43 quantities are defined in Table I. $\dot{K}(d)$ is the air kerma rate in $\left[\mu \mathrm{Gy} \mathrm{h}^{-1}\right]$ or in $\left[\mathrm{cGy} \mathrm{h}^{-1}\right], \dot{\mathrm{X}}(\mathrm{d})$ is the exposure rate in $\left[\mathrm{R} \mathrm{h}^{-1}\right]$, and $\mathrm{d}$ is a distance in $[\mathrm{cm}]$ on the transverse axis of the source. This distance, $d$, must be large enough so that the source can be approximated as a point source. $\dot{\mathrm{D}}\left(\mathrm{r}_{0}, \theta_{0}\right)$ is the dose rate for $\mathrm{r}_{0}=1 \mathrm{~cm}$ and $\theta_{0}=\pi / 2$. In the expression of $G(r, \theta), x$ and $y$ are the coordinates of the dose point.

\section{Measurements}

Exposure and dose rates for individual seeds were measured using thermoluminescent dosimeters, TLD-100 LiF (Harshaw-Bicron, Solon, OH), in air and in a solid water phantom manufactured by Radiation Measurements, Inc. (Middleton, WI). Two different TLD types were used: $3.1 \times 3.1 \times 0.9 \mathrm{~mm}^{3}$ chips and $3.1 \mathrm{~mm}$ length rods with a $1 \mathrm{~mm}$ diameter. One hundred and fifteen new TLD chips and 16 TLD rods were obtained from the supplier. The TLDs were stored in 96-well cell culture trays, each TLD having a unique identifier for its position in the tray. The position of each TLD remained constant during the experiments because each TLD had a different calibration factor. They were handled with vacuum tweezers to avoid adding any impurity or scratch on the surface.

The detectors were first annealed in a Harshaw oven set at $400^{\circ} \mathrm{C}$ for one hour, followed by 8 hours at $80^{\circ} \mathrm{C}$. This annealing process was repeated each time a new measurement using the same TLDs was needed. Before any measurement, the TLDs were calibrated using the x-ray unit at the Texas A\&M University Nuclear Science Center, which is a Norelco MG 300 operated at $250 \mathrm{kVp}$ and $10 \mathrm{~mA}$. The x-ray beam was filtered by $3.2 \mathrm{~mm}$ of lead to stop as many low energy x-rays as possible so that the beam would be as 
monoenergetic as possible and as close to the average ${ }^{198} \mathrm{Au}$ photon energy as possible. The resulting filtered calibration beam was centered on $200 \mathrm{keV}$, with a Half-Value Layer of 0.45 $\mathrm{cm}$ of copper. The forty-minute running time lead to a 5R exposure with an accuracy of about $\pm 3 \%$. At least 24 hours post-irradiation, to allow for the reading to stabilize, the TLD response was read using a Harshaw TLD reader 3500. The charge collected during this process was in [nC] and lead to the calculation of a calibration factor unique for each TLD, $\mathrm{k}_{\mathrm{cal}}$, in units of [R $\left.\mathrm{nC}^{-1}\right]$.

Dose rates were measured three times, using three different ${ }^{198} \mathrm{Au}$ seeds in order to obtain better statistics. A complete set of measurements required approximately ten days per seed. Each seed was placed in the reactor for a period of time necessary to get an activity of approximately $90 \mathrm{mCi}$ per seed. The activity of each seed was checked using both a dose calibrator and a HPGe detector. After careful energy and efficiency calibration of the HPGe detector using a ${ }^{152} \mathrm{Eu}$ point source, the error on the measured gold activity was equal to about $1 \%$. After activation, the seed was first used to measure the air kerma strength, $S_{k}$, and then dose rates in the solid water phantom.

The in-air experimental setup consisted of the radioactive seed placed at one end of a holding device, $50 \mathrm{~cm}$ away from 4 TLDs placed at the other end. The radiation scattering from this holder has been evaluated and found negligible. The readings of the 4 TLDs were averaged to get better statistics. The TLDs were exposed for approximately three days so that the dose received was $3 \mathrm{cGy}$, and then read and annealed to be ready for the next seed.

Next the seed was placed in the solid water phantom which had previously been loaded with TLDs in the last row, in a "L pattern" (see Fig. 3). The other holes of the phantom had been filled with water to have a uniform material between the source and the detectors. 
The exposure time was chosen so that the minimum dose delivered to a TLD was 3 cGy. The source was then temporarily removed while the first set of TLDs were replaced by other TLDs positioned in the line of holes closer to the source. The same process was used until all measurements were done. In this way, none of the TLDs was shielded from the source by another TLD, and the decrease in source activity was approximately compensated by the decrease in $\mathrm{r}^{2}$, leading to similar exposure times.

The readings of TLD chips irradiated by the ${ }^{198} \mathrm{Au}$ seed were converted to dose rates and air kerma strength using the following equations ${ }^{31}$ :

$$
\begin{aligned}
& \frac{\dot{\mathrm{D}}_{\mathrm{w}}}{\mathrm{S}_{\mathrm{k}}}(\mathrm{r})=\frac{\mathrm{TL}_{\mathrm{net,i}} \mathrm{k}_{\mathrm{cal}, \mathrm{i}} \mathrm{C}_{\mathrm{w}}(\mathrm{r})}{\mathrm{S}_{\mathrm{k}} \delta \mathrm{t} \mathrm{E}(\mathrm{r})} \\
& \frac{\mathrm{S}_{\mathrm{k}}}{\mathrm{A}_{\text {app }}}=\mathrm{d}^{2} \frac{\mathrm{TL}_{\text {net, }, \mathrm{i}} \mathrm{k}_{\mathrm{cal}, \mathrm{i}} \mathrm{C}_{\mathrm{a}}(\mathrm{d})}{\mathrm{A}_{\text {app }} \delta \mathrm{t} E(\mathrm{~d})}
\end{aligned}
$$

The dose rate in water at $\mathrm{r}[\mathrm{cm}]$ per unit air kerma strength is $\dot{\mathrm{D}}_{\mathrm{w}} / \mathrm{S}_{\mathrm{k}}(\mathrm{r})$ and is in units of $\left[\mathrm{cGy} \mathrm{h}^{-1} \mathrm{U}^{-1}\right]$. The direct reading from the $\mathrm{i}^{\text {th }}$ TLD placed at $\mathrm{r}[\mathrm{cm}]$ from the center of the source is $\mathrm{TL}_{\mathrm{net}, \mathrm{i}}$, which is corrected for the background and the chip factor, and is in units of $[\mathrm{nC}]$. The term $\mathrm{k}_{\mathrm{cal}, \mathrm{i}}$ is the charge to exposure conversion factor for a specific TLD, in units of $\left[\mathrm{RnC}^{-1}\right], \mathrm{t}$ is the irradiation time, and $\delta \mathrm{t}$ is the decay correction factor equal to $\left(1-\mathrm{e}^{-\lambda t}\right) / \lambda . \mathrm{C}_{\mathrm{w}}(\mathrm{r})$ and $\mathrm{C}_{\mathrm{a}}(\mathrm{d})$ are the exposure to dose conversion factor in water and air, in units of [cGy $\mathrm{R}^{-1}$. The term $\mathrm{A}_{\text {app }}$ is the apparent activity in units of [mCi] and $\mathrm{d}$ is the distance between the center of the source and the TLD. E(r) is the relative energy-response function, unitless, that accounts for the variation of sensitivity of each TLD with photon energy in $\operatorname{air}^{32}$. 


\section{Monte Carlo calculations}

The Monte Carlo code MCNP version $4 \mathrm{C}^{27}$ was used to estimate dose rates in water and exposure rates in air. The source was modeled as a cylinder of ${ }^{198} \mathrm{Au}$ inside a shell of Platinum, as shown on Fig. 1. The source was placed in the middle of a simulated sphere of water or air, with one or several detectors placed around the source.

In the case of the evaluation of exposure in air, the diameter of the sphere was equal to $50 \mathrm{~cm}$ and the space outside the sphere was void so that no particles were tracked further. One $0.2 \mathrm{~cm}$ thick ring detector was placed at $30 \mathrm{~cm}$ from the source, perpendicular to its longitudinal axis. The effect of the size of the detector and its position on the transverse axis have been studied and determined to be negligible for detector thickness ranging from 0.1 to $0.4 \mathrm{~cm}$, and radial distances greater than $20 \mathrm{~cm}$. Different sizes of the air sphere surrounding the source and detector have also been used in order to monitor the effect on the dose. This effect was also negligible as long as there was at least $5 \mathrm{~cm}$ between the detector and the void boundary. That can be explained by the fact that there was minimal scattering, including backscattering, in air.

In the case of the calculation of dose in water, the diameter of the sphere was set to 30 $\mathrm{cm}$ to match the size of the solid-water phantom used in the experiments, and to provide a geometry and size close to that used in studies of ${ }^{192} \mathrm{Ir}$, whose average gamma ray energy is similar to that of ${ }^{198} \mathrm{Au}^{5,8,10,13,33}$. The space outside of the sphere was void. The detectors were again modeled as rings with thickness ranging from $0.02 \mathrm{~cm}$ for dose points within $2 \mathrm{~cm}$ of the source to $0.06 \mathrm{~cm}$ for greater distances. The detectors were placed using the same geometry as in Fig. 3. The size of these detectors was chosen so that the flux of primary 
photons was approximately constant in the detector and the range of the most energetic secondary electrons was less than the dimension of the detector.

The default energy cutoff for both electrons and photons in MCNP 4C2, $1 \mathrm{keV}$, was

used. Only the three gammas and eight of the x-rays were used in the simulation of the ${ }^{198} \mathrm{Au}$ spectrum. The $\mathrm{x}$-rays chosen are those having a yield above $0.1 \%$ because there is no detectable difference in the results when the other x-rays are added. A simulation with the three beta particles was done to check the effect of betas on the dose and it confirmed that none of them escape from the source encapsulation to reach a detector.

The number of photon histories per simulation was chosen to have both the ten statistical checks built into MCNP give acceptable results and have a relative error at each detector of less than $1 \%$. These results were obtained with a maximum of 2 billion particles using the mode photon only. The error associated with the fact that electrons were not followed after their birth was minimized by choosing appropriate detector sizes in the mode photon only (detector dimension larger than the range of the most energetic secondary electrons).

\section{RESULTS AND DISCUSSION}

\section{A. Air kerma strength, $S_{k}$}

The air kerma strength has been calculated using MCNP 4C2 and measured in air, as the kerma rate at $1 \mathrm{~m}$ on the transverse axis times the square of the distance. The results per unit apparent activity and per unit activity are given in Table II. Those results are in good agreement with the $2.059\left[\mathrm{U} \mathrm{mCi}^{-1}\right]$ for $\mathrm{S}_{\mathrm{k}} / \mathrm{A}_{\text {app }}$ and $1.832\left[\mathrm{U} \mathrm{mCi}^{-1}\right]$ for $\mathrm{S}_{\mathrm{k}} / \mathrm{A}$ specified by the AAPM Task Group 32 in the recommendations on brachytherapy source strength 
specification $^{34}$. The value of the ratio $\mathrm{A} / \mathrm{A}_{\text {app }}$ is then 1.1287. The measured and calculated values of $S_{k} / A_{a p p}$ found in this study are also in good agreement with a $1.27 \%$ difference.

The value of the measured air kerma strength is the average of three measurements, each using four TLDs. The standard deviation of the average of these 12 values is $0.0533 \mathrm{U}$ $\mathrm{mCi}^{-1}$. The MCNP values of $\mathrm{S}_{\mathrm{k}}$ are also averaged over several runs using different starting random numbers. Different detector sizes and source to dose point distances have been used as well to check the consequences on the exposure. The final size and position of the detector were chosen once the results were converging toward the same value, regardless of the size and position of the sampling volume.

\section{B. Dose rate constant, $\Lambda$}

The dose rate constant is defined as the dose rate per unit air kerma strength at the reference point $\left(r_{0}=1 \mathrm{~cm}\right)$ on the transverse axis of the source $\left(\theta_{0}=90^{\circ}\right)$. Table III presents both measured and MCNP 4C2 results of $\Lambda$, in units of $\left[\mathrm{cGy} \mathrm{h}^{-1} \mathrm{U}^{-1}\right]$. The value of the measured dose rate constant is the average of the data obtained during the three measurement sets.

\section{The Geometry factor, $G(r, \theta)$}

The values of the geometry factor for the ${ }^{198} \mathrm{Au}$ seed have been calculated using the equation of Table I. The values of $G(r, \theta)$ times $r^{2}$ are given in Table IV. For distances greater than or equal to $5 \mathrm{~cm}$ on the longitudinal axis, the product of the geometry factor by the square of the distance $r$ is equal to 1 , which means that $G(r, \theta)$ is equal to $1 / r^{2}$, which is the point source approximation. The same is true on the transverse axis for distances greater than or equal to $3 \mathrm{~cm}$. Thus the point source approximation can be used for the geometry factor of 
the ${ }^{198} \mathrm{Au}$ source for distances greater than or equal to $5 \mathrm{~cm}$. Furthermore, using this point source approximation instead of the line approximation for distances greater than or equal to 2 $\mathrm{cm}$ gives a maximum difference of $0.3 \%$, which is negligible.

\section{The radial dose function, $g(r)$}

The radial dose function, $\mathrm{g}(\mathrm{r})$, as derived from measurements and MCNP calculations is plotted on Fig. 4 and tabulated in Table V. It is derived from dose rates and geometry factors at different distances, $r$, on the transverse axis, $\theta=90^{\circ}$. Dale's polynomial for ${ }^{198} \mathrm{Au}$, which was obtained by a fit to data from several authors, is also included because of its wide acceptance $^{2}$. The measured point at $\mathrm{r}=0.5 \mathrm{~cm}$ is not shown because its value, 0.7992 , in comparison to the MCNP value, was indicative of detector/source positioning error. The dotted lines represent calculated and experimental data, while the solid lines are polynomial fits to these data.

MCNP values are within $2.2 \%$ of those of Dale. MCNP data can be approximated by the second-order polynomial $y=-0.0017 x^{2}+0.0086 x+0.9921$. Measured $g(r)$ values are quite variable but are within $8 \%$ of MCNP data. The oscillations in the measured $\mathrm{g}(\mathrm{r}) \mathrm{can}$ be explained by the errors on the measured dose rates, such as for points that are within $1 \mathrm{~cm}$ from the source. In addition, the radial dose function is proportional to the ratio of two different dose rates on the transverse axis. The error propagation of these two dose rates amplifies the error on $\mathrm{g}(\mathrm{r})$. Nevertheless, these values correspond well with those found in previous studies for radioisotopes with similar energies ${ }^{35}$. 


\section{E. The anisotropy function, $F(r, \theta)$}

Values of the anisotropy function, $\mathrm{F}(\mathrm{r}, \theta)$ were obtained from measured data and from MCNP data for values of $\theta$ varying from $0^{\circ}$ to $90^{\circ}$, and of $\mathrm{r}$ varying from 0.5 to $10 \mathrm{~cm}$. They are presented in Tables VI and VII. The measured results are plotted in comparison with the MCNP results in Fig. 5. Each graph represents the anisotropy factor for two values of r, and from MCNP (solid lines) and measurement (dotted lines) based data.

MCNP curves appear as expected, i.e. increasing up to unity as $\mathrm{r}$ increases. Measured data fluctuate compared to MCNP data, especially for short radial distances (r equal to 0.5 and $1 \mathrm{~cm})$. These fluctuations may be explained by experimental errors that are greater for short distances than for larger distances. In addition, variations of the measured anisotropy function can also be attributed to interpolation when converting measured dose rates in the rectangular coordinate system to dose rates in the polar coordinate system. However, the variation between MCNP and measured data decreases as the radial distance increases. This is another confirmation that experimental errors are larger for short distances.

The calculated anisotropy function can be approximated by a fourth order polynomial for each value of radial distance, $r$, such as $F(r, \theta)=a \theta^{4}+b \theta^{3}+c \theta^{2}+d \theta+e$. The parameters for the polynomials fit are described in Table VIII.

\section{F. The anisotropy factor, $\phi_{\mathrm{an}}(\mathrm{r})$, and anisotropy constant, $\bar{\phi}_{\mathrm{an}}$}

For each radial distance, $r$, values of the anisotropy factor, $\phi_{\mathrm{an}}(\mathrm{r})$, are obtained by integration of the dose rate times $\sin \theta$ over angles ranging from 0 to $\pi$, divided by twice the dose rate on the transverse axis. The formula is given in Table I. A fit to the calculated and 
measured dose rate values times $\sin \theta$ is obtained, allowing the integration. The results are given in Table IX, based on both MCNP and measured data.

The anisotropy factor allows the simplification of Eq. (1) when the source is approximated as a point source. The calculated values of $\phi_{\mathrm{an}}(\mathrm{r})$ are all greater or equal to 0.965, demonstrating that the gold source is more isotropic in comparison to lower energy sources such as ${ }^{103} \mathrm{Pd}$ or ${ }^{125} \mathrm{I}$. The value of the anisotropy constant, $\bar{\phi}_{\mathrm{an}}$, demonstrates that seed orientation has only a small effect on overall dose distribution, allowing a more uniform dose to be delivered to the organ.

\section{CONCLUSION}

Dosimetric characteristics of the ${ }^{198} \mathrm{Au}$ brachytherapy source have been calculated and measured in solid water using LiF TLD chips and rods. These parameters were the air kerma strength, $S_{k}$, the dose rate constant, $\Lambda$, the geometry factor, $G(r, \theta)$, the radial dose function, $\mathrm{g}(\mathrm{r})$, the anisotropy function, $\mathrm{F}(\mathrm{r}, \theta)$, the anisotropy factor, $\phi_{\mathrm{an}}(\mathrm{r})$, and the anisotropy constant, $\bar{\phi}_{\mathrm{an}}$. These measurements were performed following the AAPM TG-43 recommendations, and were simulated using MCNP 4C2. Measurements and MCNP values are found to be in good agreement, with dose rates measured in solid water staying within $\pm 6 \%$ of the MCNP calculated results, except for few points near or on the 45-degree line and very close to the source.

This work was performed under the auspices of the U.S. Department of Energy by the University of California, Lawrence Livermore National Laboratory under Contract No. W-7405-Eng-48. 


\section{REFERENCES}

${ }^{1}$ E. B. Butler, P. T. Scardino, B. S. Teh, B. M. Uhl, W. G. Guerriero, C. E. Carlton, B. M. Berner, W. S. Dennis, L. S. Carpenter, H. H. Lu, J. K. Chiu, T. S. Kent, and S. Y. Woo, "The Baylor College of Medicine experience with gold seed implantation," Seminars in Surgical Oncology 13, 406-418 (1997).

${ }^{2}$ R. G. Dale, "Some theoretical derivations relating to the tissue dosimetry of brachytherapy nuclides, with particular reference to iodine-125," Med. Phys. 10, 176-183 (1983).

${ }^{3}$ R. Nath, L. L. Anderson, G. Luxton, K. A. Weaver, J. F. Williamson, and A. S. Meigooni, "Dosimetry of interstitial brachytherapy sources: recommendations of the AAPM Radiation Therapy Committee Task Group No. 43. American Association of Physicists in Medicine," Med. Phys. 22, 209-234 (1995).

${ }^{4}$ J. Borg and D. W. Rogers, "Spectra and air-kerma strength for encapsulated ${ }^{192}$ Ir sources," Med. Phys. 26, 2441-2444 (1999).

${ }^{5}$ S. H. Cho, R. Muller-Runkel, and W. F. Hanson, "Determination of the tissue attenuation factor along two major axes of a high dose rate (HDR) ${ }^{192}$ Ir source," Med. Phys. 26, 14921497 (1999).

${ }^{6}$ G. M. Daskalov, R. S. Baker, D. W. Rogers, and J. F. Williamson, "Dosimetric modeling of the microselectron high-dose rate ${ }^{192}$ Ir source by the multigroup discrete ordinates method," Med. Phys. 27, 2307-2319 (2000).

${ }^{7}$ M. Ghiassi-Nejad, M. Jafarizadeh, M. R. Ahmadian-Pour, and A. R. Ghahramani, "Dosimetric characteristics of ${ }^{192}$ Ir sources used in interstitial brachytherapy," Appl. Radiat. Isot. 55, 189-195 (2001). 
${ }^{8}$ P. Karaiskos, A. Angelopoulos, L. Sakelliou, P. Sandilos, C. Antypas, L. Vlachos, and E. Koutsouveli, "Monte Carlo and TLD dosimetry of an ${ }^{192} \operatorname{Ir}$ high dose-rate brachytherapy source," Med. Phys. 25, 1975-1984 (1998).

${ }^{9}$ A. Kirov, J. F. Williamson, A. S. Meigooni, and Y. Zhu, "TLD, diode and Monte Carlo dosimetry of an ${ }^{192}$ Ir source for high dose-rate brachytherapy," Phys. Med. Biol. 40, 20152036 (1995).

${ }^{10}$ J. A. Meli, A. S. Meigooni, and R. Nath, "On the choice of phantom material for the dosimetry of ${ }^{192}$ Ir sources," Int. J. Radiat. Oncol. Biol. Phys. 14, 587-594 (1988).

${ }^{11}$ R. K. Valicenti, A. S. Kirov, A. S. Meigooni, V. Mishra, R. K. Das, and J. F. Williamson, "Experimental validation of Monte Carlo dose calculations about a high-intensity Ir-192 source for pulsed dose-rate brachytherapy," Med. Phys. 22, 821-829 (1995).

${ }^{12}$ K. R. Russell and A. Ahnesjo, "Dose calculation in brachytherapy for a ${ }^{192} \operatorname{Ir}$ source using a primary and scatter dose separation technique," Phys. Med. Biol. 41, 1007-1024 (1996).

${ }^{13}$ R. Wang and R. S. Sloboda, "Monte Carlo dosimetry of the VariSource high dose rate ${ }^{192} \mathrm{Ir}$ source," Med. Phys. 25, 415-423 (1998).

${ }^{14}$ D. M. Gearheart, A. Drogin, K. Sowards, A. S. Meigooni, and G. S. Ibbott, "Dosimetric characteristics of a new ${ }^{125}$ I brachytherapy source," Med. Phys. 27, 2278-2285 (2000).

${ }^{15}$ Z. Li, J. J. Fan, and J. R. Palta, "Experimental measurements of dosimetric parameters on the transverse axis of a new ${ }^{125}$ I source," Med. Phys. 27, 1275-1280 (2000).

${ }^{16}$ R. Nath and A. Melillo, "Dosimetric characteristics of a double wall ${ }^{125} \mathrm{I}$ source for interstitial brachytherapy," Med. Phys. 20, 1475-1483 (1993).

${ }^{17}$ R. S. Sloboda and G. V. Menon, "Experimental determination of the anisotropy function and anisotropy factor for model 6711 I-125 seeds," Med. Phys. 27, 1789-1799 (2000). 
${ }^{18}$ Z. Li, J. R. Palta, and J. J. Fan, "Monte Carlo calculations and experimental measurements of dosimetry parameters of a new ${ }^{103} \mathrm{Pd}$ source," Med. Phys. 27, 1108-1112 (2000).

${ }^{19}$ A. S. Meigooni, K. Sowards, and M. Soldano, "Dosimetric characteristics of the InterSource103 palladium brachytherapy source," Med. Phys. 27, 1093-1100 (2000).

${ }^{20}$ D. E. Mellenberg, Jr. and E. C. Pennington, ${ }^{103} \mathrm{Pd}$ loaded cartridge air kerma strength verification," Med. Dosim. 24, 73-75 (1999).

${ }^{21}$ R. Nath, N. Yue, K. Shahnazi, and P. J. Bongiorni, "Measurement of dose-rate constant for ${ }^{103} \mathrm{Pd}$ seeds with air kerma strength calibration based upon a primary national standard," Med. Phys. 27, 655-658 (2000).

${ }^{22}$ R. E. Wallace and J. J. Fan, "Dosimetric characterization of a new design 103 palladium brachytherapy source," Med. Phys. 26, 2465-2470 (1999).

${ }^{23}$ S. K. Jani, E. C. Pennington, and B. M. Knosp, "Dose anisotropy around an Au-198 seed source," Med. Phys. 16, 632-635 (1989).

${ }^{24}$ C. C. Ling, Z. C. Gromadzki, S. N. Rustgi, and J. H. Cundiff, "Directional dependence of radiation fluence from ${ }^{192}$ Ir and ${ }^{198}$ Au sources," Radiology 146, 791-792 (1983).

${ }^{25}$ N. Reynaert, F. Verhaegen, Y. Taeymans, M. Van Eijkeren, and H. Thierens, "Monte Carlo calculations of dose distributions around ${ }^{32} \mathrm{P}$ and ${ }^{198} \mathrm{Au}$ stents for intravascular brachytherapy," Med. Phys. 26, 1484-1491 (1999).

${ }^{26}$ L. Sakelliou, K. Sakellariou, K. Sarigiannis, A. Angelopoulos, A. Perris, and G. Zarris, "Dose rate distributions around $60 \mathrm{Co},{ }^{137} \mathrm{Cs},{ }^{198} \mathrm{Au},{ }^{192} \mathrm{Ir},{ }^{241} \mathrm{Am},{ }^{125} \mathrm{I}$ (models 6702 and 6711) brachytherapy sources and the nuclide ${ }^{99}$ Tcm," Phys. Med. Biol. 37, 1859-1872 (1992).

${ }^{27}$ J. F. Briesmeister, MCNP a general Monte Carlo N-Particle Transport code version 4C2, Los Alamos National Laboratory, Report No. LA-13709-M, 2001. 
${ }^{28}$ S. Y. F. Chu, L. P. Ekström, and R. B. Firestone, "The Lund/LBNL Nuclear Data Search, Version 2.0," (1999).

${ }^{29}$ C. B. Saw, A. S. Meigooni, and R. Nath, "Review of AAPM Task Group No. 43 recommendations on interstitial brachytherapy sources dosimetry. American Association of Physicists in Medicine," Med. Dosim. 23, 259-263 (1998).

${ }^{30}$ M. J. Rivard, "Refinements to the geometry factor used in the AAPM Task Group Report No. 43 necessary for brachytherapy dosimetry calculations. American Association of Physicists in Medicine," Med. Phys. 26, 2445-2450 (1999).

${ }^{31}$ J. F. Williamson, B. R. Thomadsen, and R. Nath, Brachytherapy Physics. (Medical Physics Publishing, Madison, WI, 1994).

${ }^{32}$ A. S. Meigooni, J. A. Meli, and R. Nath, "Influence of the variation of energy spectra with depth in the dosimetry of ${ }^{192}$ Ir using LiF TLD," Phys. Med. Biol. 33, 1159-1170 (1988).

${ }^{33}$ P. Karaiskos, A. Angelopoulos, P. Baras, L. Sakelliou, P. Sandilos, K. Dardoufas, and L. Vlachos, "A Monte Carlo investigation of the dosimetric characteristics of the VariSource ${ }^{192}$ Ir high dose rate brachytherapy source," Med. Phys. 26, 1498-1502 (1999).

${ }^{34}$ J. F. Williamson and R. Nath, "Clinical implementation of AAPM Task Group 32 recommendations on brachytherapy source strength specification," Med. Phys. 18, 439-448 (1991).

${ }^{35}$ A. S. Meigooni and R. Nath, "A comparison of radial dose functions for ${ }^{103} \mathrm{Pd},{ }^{125} \mathrm{I},{ }^{145} \mathrm{Sm}$, ${ }^{241} \mathrm{Am},{ }^{169} \mathrm{Yb},{ }^{192} \mathrm{Ir}$, and ${ }^{137} \mathrm{Cs}$ brachytherapy sources," Int. J. Radiat. Oncol. Biol. Phys. 22, 1125-1130 (1992). 
TABLE I. Expressions of the AAPM TG-43 quantities.

Air kerma strength, $S_{k}$

Dose rate constant, $\Lambda$

Geometry factor, $G(r, \theta)$

Radial dose function, $\mathrm{g}(\mathrm{r})$

Anisotropy function, $\mathrm{F}(\mathrm{r}, \theta)$

Anisotropy factor, $\phi_{\mathrm{an}}(\mathrm{r})$

Anisotropy constant, $\bar{\phi}_{\mathrm{an}}$
$\mathrm{S}_{\mathrm{k}}=\dot{\mathrm{K}}(\mathrm{d}) \mathrm{d}^{2}=0.876 \dot{\mathrm{X}}(\mathrm{d}) \mathrm{d}^{2}$

$\Lambda=\frac{\dot{\mathrm{D}}\left(\mathrm{r}_{0}, \theta_{0}\right)}{\mathrm{S}_{\mathrm{k}}}$

$\mathrm{G}(\mathrm{r}, \theta)= \begin{cases}\mathrm{r}^{-2} & \text { point-source approximation } \\ \frac{\beta}{\mathrm{Lrsin} \theta} & \text { line-source approximation }\end{cases}$

$G(r, \theta)=\frac{\tan ^{-1}\left(\frac{x+\frac{L}{2}}{y}\right)-\tan ^{-1}\left(\frac{x-\frac{L}{2}}{y}\right)}{L y}$ line app.

$g(r)=\frac{\dot{D}\left(r, \theta_{0}\right) G\left(r_{0}, \theta_{0}\right)}{\dot{D}\left(r_{0}, \theta_{0}\right) G\left(r, \theta_{0}\right)}$

$\mathrm{F}(\mathrm{r}, \theta)=\frac{\dot{\mathrm{D}}(\mathrm{r}, \theta) \mathrm{G}\left(\mathrm{r}, \theta_{0}\right)}{\dot{\mathrm{D}}\left(\mathrm{r}, \theta_{0}\right) \mathrm{G}(\mathrm{r}, \theta)}$

$\phi_{\mathrm{an}}(\mathrm{r})=\frac{\int_{0}^{\pi} \dot{\mathrm{D}}(\mathrm{r}, \theta) \sin \theta \mathrm{d} \theta}{2 \dot{\mathrm{D}}\left(\mathrm{r}, \theta_{0}\right)}=\frac{\int_{0}^{\pi} \mathrm{G}(\mathrm{r}, \theta) \mathrm{F}(\mathrm{r}, \theta) \sin \theta \mathrm{d} \theta}{2 \mathrm{G}\left(\mathrm{r}, \theta_{0}\right) \mathrm{F}\left(\mathrm{r}, \theta_{0}\right)}$

$\bar{\phi}_{\mathrm{an}}=\frac{\sum_{\mathrm{i}=1}^{\mathrm{M}} \phi_{\mathrm{an}}\left(\mathrm{r}_{\mathrm{i}}\right)}{\mathrm{M}}$ 
TABLE II. Measured and MCNP values for the air kerma strength, $\mathrm{S}_{\mathrm{k}}$, in units of [ $\left.\mathrm{U} \mathrm{mCi}^{-1}\right]$, per unit apparent activity, and per unit activity.

\begin{tabular}{ccc}
\hline \hline & MCNP & Measurements \\
\hline $\mathbf{S}_{\mathbf{k}} / \mathbf{A}_{\text {app }}$ & $2.0627 \pm 0.0153$ & $2.0889 \pm 0.0533$ \\
$\mathbf{S}_{\mathbf{k}} / \mathbf{A}$ & $1.8275 \pm 0.0164$ & \\
\hline
\end{tabular}

TABLE III. Measured and MCNP values for the dose rate constant, $\Lambda$, per unit air kerma strength, $\mathrm{S}_{\mathrm{k}}$, [cGy h$\left.{ }^{-1} \mathrm{U}^{-1}\right]$.

\begin{tabular}{ccc}
\hline \hline & MCNP & Measurements \\
\hline$\Lambda$ & $1.1148 \pm 0.0050$ & $1.0952 \pm 0.0774$ \\
\hline \hline
\end{tabular}


TABLE IV. Geometry factor $G(r, \theta)$ times $r^{2}$ for a ${ }^{198} \mathrm{Au}$ seed approximated by a $2.2 \mathrm{~mm}$ line source (active length).

\begin{tabular}{cccccccccccc}
\hline \hline & & & & & & $\boldsymbol{\theta}$ & & & & & \\
\hline $\mathbf{r}(\mathbf{c m})$ & $\mathbf{0}$ & $\mathbf{1 0}$ & $\mathbf{2 0}$ & $\mathbf{3 0}$ & $\mathbf{4 0}$ & $\mathbf{4 5}$ & $\mathbf{5 0}$ & $\mathbf{6 0}$ & $\mathbf{7 0}$ & $\mathbf{8 0}$ & $\mathbf{9 0}$ \\
\hline $\mathbf{0 . 5}$ & 1.051 & 1.049 & 1.042 & 1.033 & 1.021 & 1.016 & 1.010 & 1 & 0.991 & 0.986 & 0.984 \\
$\mathbf{1}$ & 1.012 & 1.012 & 1.010 & 1.008 & 1.005 & 1.004 & 1.003 & 1 & 0.998 & 0.996 & 0.996 \\
$\mathbf{1 . 5}$ & 1.005 & 1.005 & 1.005 & 1.004 & 1.002 & 1.002 & 1.001 & 1 & 0.999 & 0.998 & 0.998 \\
$\mathbf{2}$ & 1.003 & 1.003 & 1.003 & 1.002 & 1.001 & 1.001 & 1.001 & 1 & 0.999 & 0.999 & 0.999 \\
$\mathbf{3}$ & 1.001 & 1.001 & 1.001 & 1.001 & 1.001 & 1 & 1 & 1 & 1 & 1 & 1 \\
$\mathbf{4}$ & 1.001 & 1.001 & 1.001 & 1.001 & 1 & 1 & 1 & 1 & 1 & 1 & 1 \\
$\mathbf{5}$ & 1.001 & 1 & 1 & 1 & 1 & 1 & 1 & 1 & 1 & 1 & 1 \\
$\mathbf{6}$ & 1 & 1 & 1 & 1 & 1 & 1 & 1 & 1 & 1 & 1 & 1 \\
$\mathbf{7}$ & 1 & 1 & 1 & 1 & 1 & 1 & 1 & 1 & 1 & 1 & 1 \\
$\mathbf{8}$ & 1 & 1 & 1 & 1 & 1 & 1 & 1 & 1 & 1 & 1 & 1 \\
$\mathbf{9}$ & 1 & 1 & 1 & 1 & 1 & 1 & 1 & 1 & 1 & 1 & 1 \\
$\mathbf{1 0}$ & 1 & 1 & 1 & 1 & 1 & 1 & 1 & 1 & 1 & 1 & 1 \\
\hline \hline
\end{tabular}

TABLE V. Values of the radial dose function, $g(r)$, for distances ranging from 0.5 to $10 \mathrm{~cm}$, and using measured and MCNP data.

\begin{tabular}{cccccccccccccc}
\hline \hline \multicolumn{10}{c}{$\mathbf{r}(\mathbf{c m})$} \\
\hline $\mathbf{g}(\mathbf{r})$ & $\mathbf{0 . 5}$ & $\mathbf{1}$ & $\mathbf{1 . 5}$ & $\mathbf{2}$ & $\mathbf{3}$ & $\mathbf{4}$ & $\mathbf{5}$ & $\mathbf{6}$ & $\mathbf{7}$ & $\mathbf{8}$ & $\mathbf{9}$ & $\mathbf{1 0}$ \\
\hline Meas & 0.7992 & 1 & 1.0347 & 1.0278 & 0.9733 & 0.9216 & 0.9627 & 0.9379 & 0.9042 & 0.9498 & 0.9006 & 0.9317 \\
MCNP & 0.9974 & 1 & 1.0007 & 0.9995 & 1.0015 & 1.0027 & 0.9969 & 0.9854 & 0.9666 & 0.9522 & 0.9440 & 0.9097 \\
\hline \hline
\end{tabular}


TABLE VI. Values of the anisotropy function, $\mathrm{F}(\mathrm{r}, \theta)$, using MCNP data.

\begin{tabular}{cccccccccccc}
\hline \hline & & & & & & $\boldsymbol{\theta}$ & & & & & \\
\hline $\mathbf{r ~ ( c m )}$ & $\mathbf{0}$ & $\mathbf{1 0}$ & $\mathbf{2 0}$ & $\mathbf{3 0}$ & $\mathbf{4 0}$ & $\mathbf{4 5}$ & $\mathbf{5 0}$ & $\mathbf{6 0}$ & $\mathbf{7 0}$ & $\mathbf{8 0}$ & $\mathbf{9 0}$ \\
\hline $\mathbf{0 . 5}$ & 0.8033 & 0.8096 & 0.8606 & 0.9087 & 0.9483 & 0.9644 & 0.9731 & 0.9919 & 0.9973 & 1.0085 & 1 \\
$\mathbf{1}$ & 0.7851 & 0.7966 & 0.8542 & 0.9168 & 0.9539 & 0.9626 & 0.9700 & 0.9856 & 0.9962 & 1.0058 & 1 \\
$\mathbf{1 . 5}$ & 0.7851 & 0.7931 & 0.8595 & 0.9120 & 0.9516 & 0.9576 & 0.9710 & 0.9856 & 1.0004 & 1.0053 & 1 \\
$\mathbf{2}$ & 0.7917 & 0.8068 & 0.8695 & 0.9096 & 0.9545 & 0.9637 & 0.9702 & 0.9957 & 1.0104 & 1.0040 & 1 \\
$\mathbf{3}$ & 0.7941 & 0.8092 & 0.8802 & 0.9207 & 0.9555 & 0.9693 & 0.9789 & 0.9918 & 0.9934 & 1.0054 & 1 \\
$\mathbf{4}$ & 0.8012 & 0.8256 & 0.8805 & 0.9149 & 0.9523 & 0.9606 & 0.9852 & 0.9802 & 0.9792 & 1.0069 & 1 \\
$\mathbf{5}$ & 0.8059 & 0.8308 & 0.8771 & 0.8882 & 0.9625 & 0.9739 & 0.9746 & 0.9901 & 0.9872 & 1.0098 & 1 \\
$\mathbf{6}$ & 0.8134 & 0.8608 & 0.8860 & 0.8997 & 0.9790 & 0.9764 & 0.9745 & 0.9738 & 1.0062 & 1.0021 & 1 \\
$\mathbf{7}$ & 0.8221 & 0.8555 & 0.8991 & 0.9353 & 0.9651 & 0.9719 & 0.9808 & 0.9867 & 1.0063 & 1.0085 & 1 \\
$\mathbf{8}$ & 0.8287 & 0.8624 & 0.9119 & 0.9398 & 0.9691 & 0.9809 & 0.9841 & 0.9901 & 1.0126 & 1.0129 & 1 \\
$\mathbf{9}$ & 0.8291 & 0.8645 & 0.9056 & 0.9285 & 0.9581 & 0.9600 & 0.9789 & 0.9725 & 1.0016 & 0.9960 & 1 \\
$\mathbf{1 0}$ & 0.8474 & 0.8909 & 0.9217 & 0.9405 & 0.9742 & 0.9755 & 0.9924 & 1.0034 & 1.0196 & 1.0260 & 1 \\
\hline \hline
\end{tabular}


TABLE VII. Values of the anisotropy function, $\mathrm{F}(\mathrm{r}, \theta)$, using measured data.

\begin{tabular}{cccccccccccc}
\hline \hline & & & & & \multicolumn{1}{c}{$\boldsymbol{\theta}$} & & & & & \\
\hline $\mathbf{r}(\mathbf{c m})$ & $\mathbf{0}$ & $\mathbf{1 0}$ & $\mathbf{2 0}$ & $\mathbf{3 0}$ & $\mathbf{4 0}$ & $\mathbf{4 5}$ & $\mathbf{5 0}$ & $\mathbf{6 0}$ & $\mathbf{7 0}$ & $\mathbf{8 0}$ & $\mathbf{9 0}$ \\
\hline $\mathbf{0 . 5}$ & & 0.8743 & 0.8927 & 0.9731 & 1.1072 & 1.1940 & 1.1492 & 1.0434 & 0.9857 & 0.9776 & 1 \\
$\mathbf{1}$ & 0.8076 & 0.8167 & 0.9290 & 1.0221 & 1.0821 & 1.1433 & 1.1248 & 1.1333 & 1.1027 & 1.0125 & 1 \\
$\mathbf{1 . 5}$ & 0.7570 & 0.7945 & 0.8904 & 0.9286 & 0.9511 & 0.9739 & 0.9746 & 1.0418 & 1.0545 & 1.0364 & 1 \\
$\mathbf{2}$ & 0.8103 & 0.8396 & 0.8864 & 0.9204 & 0.9104 & 0.9510 & 0.9299 & 0.9755 & 1.0336 & 1.0578 & 1 \\
$\mathbf{3}$ & 0.8213 & 0.8459 & 0.9430 & 1.0076 & 1.0380 & 1.0662 & 1.0602 & 1.0802 & 1.0407 & 0.9709 & 1 \\
$\mathbf{4}$ & 0.8316 & 0.8534 & 0.9305 & 1.0218 & 1.0159 & 1.0776 & 1.0585 & 1.1198 & 1.0714 & 1.0230 & 1 \\
$\mathbf{5}$ & 0.8223 & 0.7938 & 0.8590 & 0.8914 & 0.8501 & 0.9131 & 0.9052 & 1.0104 & 1.0286 & 1.0056 & 1 \\
$\mathbf{6}$ & 0.8846 & 0.8661 & 0.8841 & 0.8883 & 0.9171 & 0.9103 & 0.9585 & 1.0160 & 1.0651 & 1.0026 & 1 \\
$\mathbf{7}$ & 0.8691 & 0.8353 & 0.9479 & 0.9501 & 0.9993 & 1.0246 & 1.0293 & 1.0108 & 1.0439 & 1.0259 & 1 \\
$\mathbf{8}$ & 0.7737 & 0.8156 & 0.8951 & 0.8690 & 0.9151 & 0.9297 & 0.9303 & 0.9549 & 0.9374 & 0.9505 & 1 \\
$\mathbf{9}$ & 0.9909 & 0.8731 & 0.9386 & 0.9403 & 0.9450 & 0.9644 & 0.9974 & 1.0521 & 1.0202 & 1.0219 & 1 \\
$\mathbf{1 0}$ & 0.8371 & 0.8669 & 0.9063 & 0.9440 & 0.8819 & 0.9584 & 0.9457 & 0.9370 & 0.9950 & 1.0603 & 1 \\
\hline \hline
\end{tabular}


TABLE VIII. Values of the parameters for the polynomial fit of the anisotropy function, $\mathrm{F}(\mathrm{r}, \theta)$.

\begin{tabular}{cccccc}
\hline \hline $\mathbf{r}(\mathbf{c m})$ & $\mathbf{a}$ & $\mathbf{b}$ & $\mathbf{c}$ & $\mathbf{d}$ & $\mathbf{e}$ \\
\hline $\mathbf{0 . 5}$ & $3 \mathrm{E}-08$ & $5 \mathrm{E}-06$ & 0.0003 & 0.0011 & 0.8017 \\
$\mathbf{1}$ & $4 \mathrm{E}-08$ & $6 \mathrm{E}-06$ & 0.0003 & 0.0004 & 0.7824 \\
$\mathbf{1 . 5}$ & $3 \mathrm{E}-08$ & $5 \mathrm{E}-06$ & 0.0003 & 0.0002 & 0.7812 \\
$\mathbf{2}$ & $2 \mathrm{E}-08$ & $3 \mathrm{E}-06$ & 0.0002 & 0.0017 & 0.7883 \\
$\mathbf{3}$ & $3 \mathrm{E}-08$ & $5 \mathrm{E}-06$ & 0.0002 & 0.0011 & 0.7909 \\
$\mathbf{4}$ & $3 \mathrm{E}-08$ & $5 \mathrm{E}-06$ & 0.0002 & 0.0008 & 0.8012 \\
$\mathbf{5}$ & $3 \mathrm{E}-08$ & $5 \mathrm{E}-06$ & 0.0002 & 0.0001 & 0.8084 \\
$\mathbf{6}$ & $1 \mathrm{E}-08$ & $2 \mathrm{E}-06$ & $8 \mathrm{E}-05$ & 0.0026 & 0.8173 \\
$\mathbf{7}$ & $1 \mathrm{E}-08$ & $2 \mathrm{E}-06$ & $6 \mathrm{E}-05$ & 0.0033 & 0.821 \\
$\mathbf{8}$ & $8 \mathrm{E}-09$ & $1 \mathrm{E}-06$ & $3 \mathrm{E}-05$ & 0.0039 & 0.8271 \\
$\mathbf{9}$ & $2 \mathrm{E}-09$ & $2 \mathrm{E}-07$ & $2 \mathrm{E}-05$ & 0.0042 & 0.8281 \\
$\mathbf{1 0}$ & $-6 \mathrm{E}-09$ & $1 \mathrm{E}-06$ & $7 \mathrm{E}-05$ & 0.0047 & 0.8481 \\
\hline \hline
\end{tabular}


TABLE IX. Values of the anisotropy factor, $\phi$ an $(r)$, and anisotropy constant, $\bar{\phi}_{\mathrm{an}}$, for distances ranging from 0.5 to $10 \mathrm{~cm}$, and using MCNP and measured data.

\begin{tabular}{lcccccccccccc}
\hline \hline \multicolumn{10}{c}{$\mathbf{r}(\mathbf{c m})$} \\
\hline$\phi_{\text {an }}(\mathbf{r})$ & $\mathbf{0 . 5}$ & $\mathbf{1}$ & $\mathbf{1 . 5}$ & $\mathbf{2}$ & $\mathbf{3}$ & $\mathbf{4}$ & $\mathbf{5}$ & $\mathbf{6}$ & $\mathbf{7}$ & $\mathbf{8}$ & $\mathbf{9}$ & $\mathbf{1 0}$ \\
& & & & & & & & & & & \\
\hline MCNP & 0.9859 & 0.9695 & 0.9668 & 0.9701 & 0.9693 & 0.9650 & 0.9665 & 0.9697 & 0.9756 & 0.9805 & 0.9691 & 0.9883 \\
Meas & 1.0215 & 1.0605 & 0.9940 & 0.9758 & 1.0155 & 1.0335 & 0.9479 & 0.9758 & 1.0080 & 0.9295 & 0.9988 & 0.9646 \\
\hline \hline
\end{tabular}

\begin{tabular}{cc}
\hline \hline & $\bar{\phi}_{\mathrm{an}}$ \\
\hline MCNP & 0.9730 \\
Meas & 0.9938 \\
\hline \hline
\end{tabular}




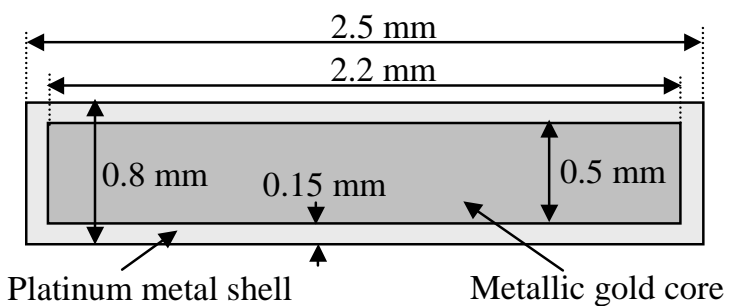

FIG. 1. Diagram of the cylindrical ${ }^{198}$ Au Engelhard brachytherapy seed.

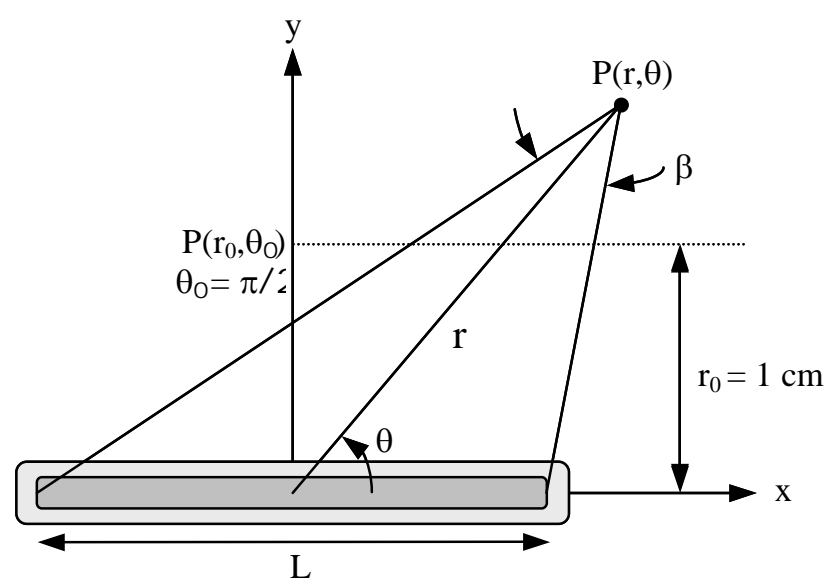

FIG. 2. Illustration of the geometry used in the dose calculation formalism recommended by AAPM TG-43. $\mathrm{P}(\mathrm{r}, \theta)$ is the dose point. 


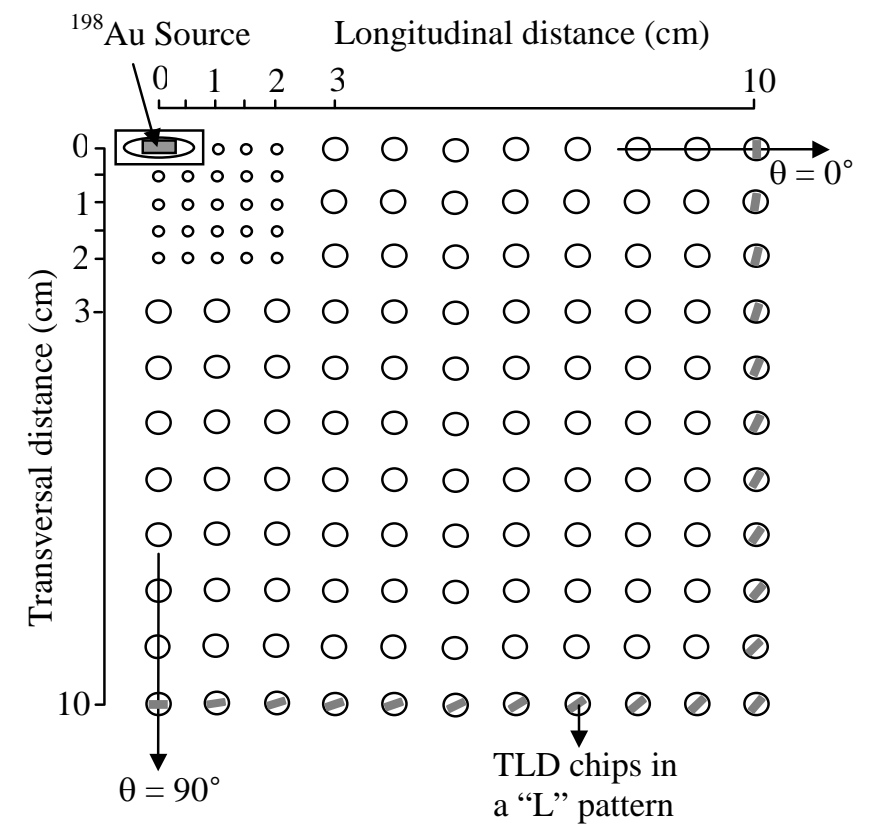

FIG. 3. Schematic of the middle slab of the solid water phantom, drilled with $3.1 \mathrm{~mm}$ and 1 mm diameter holes, showing TLD chips installed for the first of a sequence of measurements. 


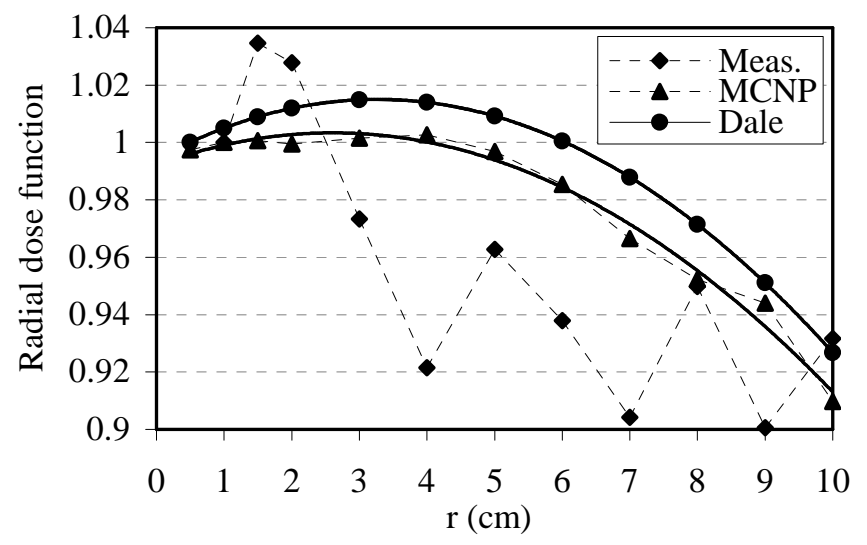

FIG. 4. Radial dose function using measured, MCNP, and Dale's polynomial data. Dotted lines are calculated and measured data. Solid lines are polynomial fits to the data. 

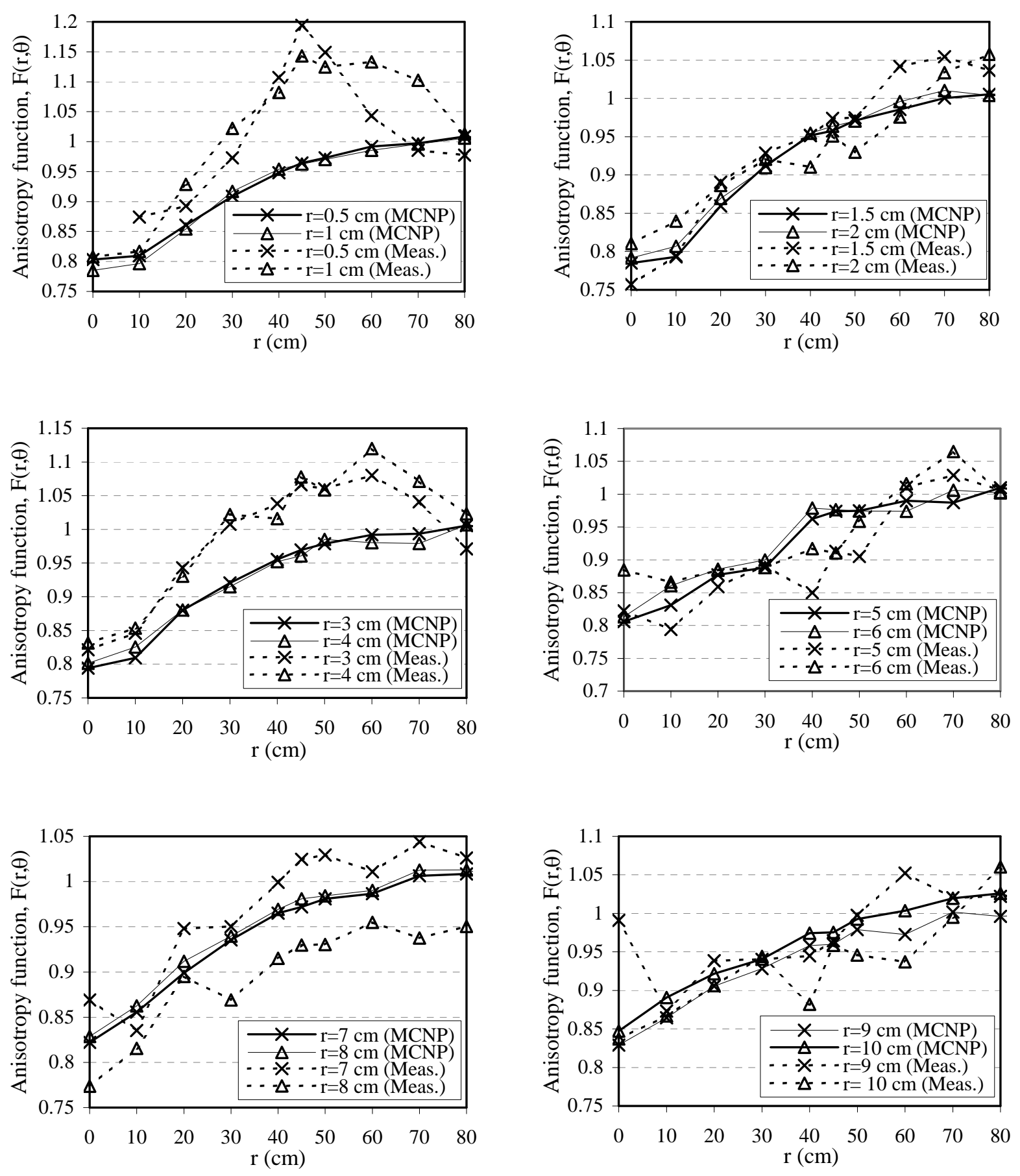

FIG. 5. Values of the anisotropy function, $F(r, \theta)$, for values of $r$ ranging from $0.5 \mathrm{~cm}$ to 10 $\mathrm{cm}$. Solid lines are values calculated from MCNP data, and dotted lines from measured data. 